\title{
Production of viable seeds from the seedling lethal mutant ppi2-2 lacking the atToc159 chloroplast protein import receptor using plastic containers, and characterization of the homozygous mutant progeny
}

\author{
Akari Tada' , Fumi Adachi ${ }^{1}$, Tomohiro Kakizaki ${ }^{2}$ and Takehito Inaba ${ }^{1}$ * \\ 1 Department of Agricultural and Environmental Sciences, Faculty of Agriculture, University of Miyazaki, Miyazaki, Japan \\ ${ }^{2}$ National Institute of Vegetable and Tea Science, Tsu, Japan
}

\section{Edited by:}

Kentaro Inoue, University of California at Davis, USA

\section{Reviewed by:}

Toshiaki Mitsui, Niigata University, Japan

Mark Findlay Belmonte, University of Manitoba, Canada

Meshack Afithile, Western Illinois

University, USA

\section{${ }^{*}$ Correspondence:}

Takehito Inaba, Department of Agricultural and Environmental Sciences, Faculty of Agriculture, University of Miyazaki, 1-1

Gakuenkibanadai-nishi, Miyazaki 889-2192, Japan

e-mail: tinaba@cc.miyazaki-u.ac.jp
Biogenesis of chloroplasts is essential for plant growth and development. A number of homozygous mutants lacking a chloroplast protein exhibit an albino phenotype. In general, it is challenging to grow albino Arabidopsis plants on soil until they set seeds. Homozygous albino mutants are usually obtained as progenies of heterozygous parents. Here, we describe a method of recovering seeds from the seedling lethal Arabidopsis mutant ppi2-2, which lacks the atToc159 protein import receptor at the outer envelope membrane of chloroplast. Using plastic containers, we were able to grow homozygous ppi2-2 plants until these set seed. Although the germination rate of the harvested seeds was relatively low, it was still sufficient to allow us to further analyze the ppi2-2 progeny. Using ppi2-2 homozygous seeds, we were able to analyze the role of plastid protein import in the light-regulated induction of nuclear genes. We propose that this method be applied to other seedling lethal Arabidopsis mutants to obtain homozygous seeds, helping us further investigate the roles of plastid proteins in plant growth and development.

Keywords: albino, Arabidopsis, chloroplast, ppi2-2 mutant, protein import, seed

\section{INTRODUCTION}

Plastids such as chloroplasts in photosynthetic plant cells are believed to have evolved from a cyanobacterium-like ancestor (Dyall etal., 2004). During evolution, most of the genes encoded by the bacterial ancestor were transferred to the nuclear genome of the host. Therefore, the expression of nuclear genes encoding plastid proteins and the import of those proteins into plastids are essential for plastid biogenesis. The key player involved in delivering nuclear-encoded proteins into plastids is the translocon at the outer envelope membrane of chloroplasts (TOC) and the translocon at the inner envelope membrane of chloroplasts (TIC) complex (Inaba and Schnell, 2008; Li and Chiu, 2010; Jarvis and Lopez-Juez, 2013). The TOC-TIC complex was first isolated through biochemical purification (Kessler etal., 1994; Schnell etal., 1994). Molecular genetic analysis of identified components using Arabidopsis indicated that these were indeed indispensable for plastid biogenesis (Jarvis etal., 1998; Bauer etal., 2000; Chou etal., 2003; Constan et al., 2004a,b; Ivanova et al., 2004; Kubis et al., 2004; Inaba etal., 2005; Kovacheva etal., 2005; Teng etal., 2006; Kikuchi et al., 2013).

Because of their key roles in plastid protein import, a number of mutants defective in TOC or TIC proteins exhibit severe developmental arrest, resulting in embryo and seedling lethality. These lethal phenotypes have made it difficult to characterize in more detail the roles of the TOC-TIC complex in plant growth and development. For instance, the homozygous plastid protein import 2 (ppi2) mutant that lacks the major protein import receptor of plastids, atToc159, exhibits seedling lethality due to its severe albino phenotype (Bauer et al., 2000; Kakizaki et al., 2009). Therefore, we can only obtain bulk seeds from heterozygous ppi2 (ppi2/+) plants. When the progeny of ppi2-2/+ is grown in the dark, it is virtually impossible to discriminate between homozygous ppi2-2 and the heterozygous ppi2-2/+. Hence, to further uncover the role of plastid protein import in plant growth and development, it is necessary to propagate seeds from seedling lethal, albino mutants such as the homozygous ppi2.

In this paper, we describe a method for generating viable seeds from the seedling lethal Arabidopsis mutant ppi2-2, which lacks the major protein import receptor of plastids (Bauer et al., 2000; Kakizaki et al., 2009). Using these seeds, we investigated the photomorphogenic response of the ppiz-2 mutant and showed that the TOC-TIC pathway and the light-induced gene expression are tightly coordinated with each other. Our method also provides clues on how to obtain viable seeds from other albino Arabidopsis plants, allowing us to uncover the roles of plastid proteins in plant growth and development in more detail.

\section{MATERIALS AND METHODS PLANT MATERIALS}

All experiments were performed on Arabidopsis thaliana accession Columbia (Col-0). The ppiz-2 mutant has been described elsewhere (Kakizaki et al., 2009). Wild-type and ppi2-2/+ seeds were obtained from plants grown on soil. 


\section{GROWTH CONDITIONS FOR RECOVERING HOMOZYGOUS ppi2-2 SEEDS}

An overview of the growth method is summarized in Figure 1A. The progeny of ppi2-2/+ plants were first grown on plates $(150 \mathrm{~mm}$ in diameter) containing $0.5 \%$ agar, $1 \%$ sucrose, and $0.5 \times \mathrm{MS}$ salts at $\mathrm{pH}$ 5.8. To synchronize germination, all seeds were maintained at $4^{\circ} \mathrm{C}$ for 2 days after sowing. Plants were grown under continuous white light ( $80 \mu \mathrm{mol} \mathrm{m} \mathrm{m}^{-2} \mathrm{~s}^{-1}$, unless specified) at $22^{\circ} \mathrm{C}$ and $50 \%$ relative humidity in a growth chamber (LPH-350S, NK system). After 14-18 days, homozygous ppi2-2 plants were transferred to small size, round-shaped Ziploc ${ }^{\circledR}$ containers (width $108 \mathrm{~mm} \times$ depth $108 \mathrm{~mm} \times$ height $56 \mathrm{~mm}, 236 \mathrm{ml}$ container size, Asahi Kasei Co. Ltd., Japan; see Figures 1B and 2) containing $0.8 \%$ agar, $3 \%$ sucrose, and $0.5 \times$ MS salts at $\mathrm{pH} 5.8$. We believe this container is most similar to the Ziploc ${ }^{\circledR}$ brand Container with the Smart Snap ${ }^{\circledR}$ Seal Extra Small Bowl (8 ounces, S.C. Johnson \& Son, Inc., Howe St Racine, WI, USA) in the United State. Typically, 14-18 days old ppi2-2 plants have four to six small true leaves. It is important to choose well-developed ppi2-2 plants for subsequent cultivation in Ziploc ${ }^{\circledR}$ containers. To avoid excess humidity and facilitate air circulation in the pot, each pot had four holes that were sealed with two layers of surgical tape (Figure 1). We made those holes using a knife. In most cases, we placed five to seven plants in each pot. At this point, the lid was tightly sealed and taped with surgical tape (Figure 1A, middle). We continued to grow the plants until they started bolting (Figure 2A, right). Once the plants

A

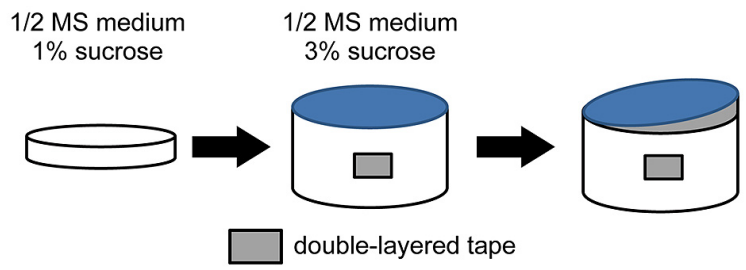

B

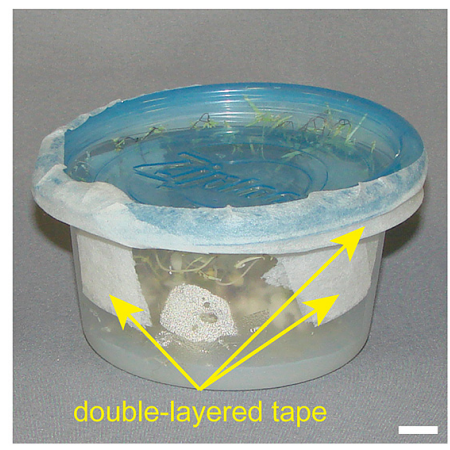

FIGURE 1 | Overview of homozygous ppi2-2 cultivation using plates and Ziploc ${ }^{\circledR}$ containers. (A) Homozygous ppi2-2 plants were first grown in MS plates (left) and then transferred into a Ziploc ${ }^{\circledR}$ container (middle). The Ziploc ${ }^{\circledR}$ container has four holes covered with double-layered surgical tape. At a later stage, the lid of the Ziploc ${ }^{\circledR}$ container was partially opened (right), and a gap between the lid and the container was sealed with double-layered surgical tape. (B) Ziploc ${ }^{\circledR}$ container used in this study. Bar $=$ approximately $1 \mathrm{~cm}$.
A

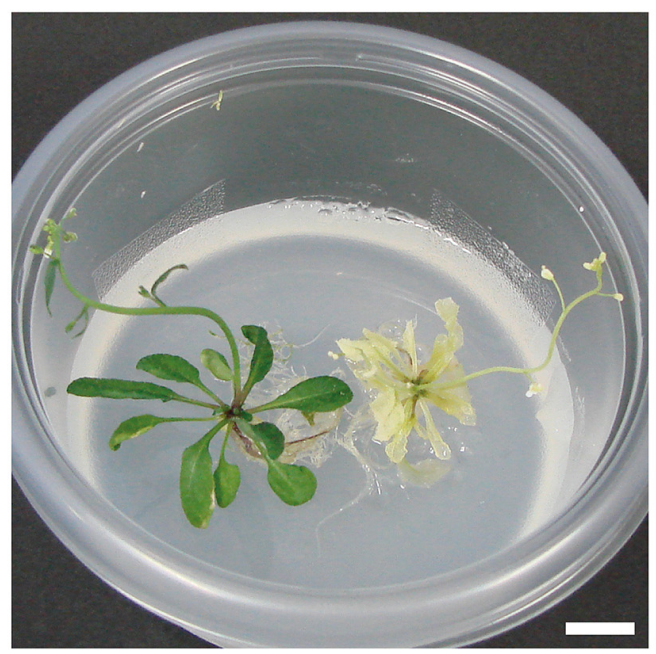

B

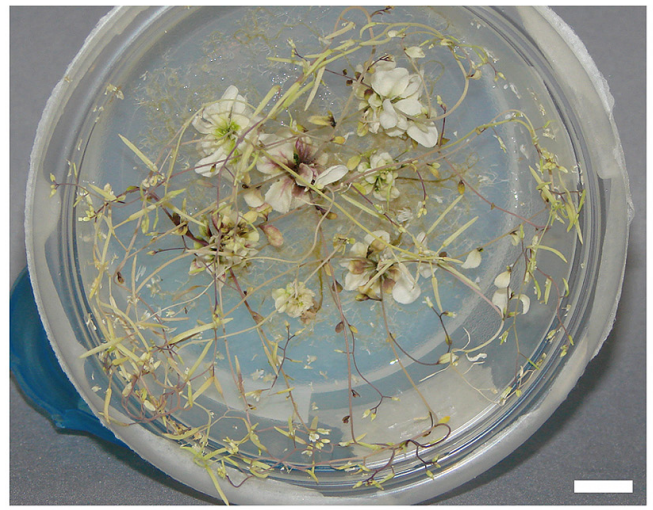

FIGURE 2 | Phenotype of homozygous ppi2-2 plants grown in Ziploc ${ }^{\circledR}$ containers. (A) Representative phenotype of wild-type (left) and ppi2-2 (right) plants grown in Ziploc ${ }^{\circledR}$ containers. After transferring the plants from plates, they were grown in a Ziploc ${ }^{\circledR}$ container for 10 days.

Bar $=$ approximately $1 \mathrm{~cm}$. (B) At a later stage, the ppi2-2 plants set seeds in the Ziploc ${ }^{\circledR}$ container. Bar $=$ approximately $1 \mathrm{~cm}$

had started bolting, the lid was partially opened and taped with two layers of surgical tape (Figure 1B). The plants were then harvested after they set seeds (Figure 2B). The harvested plants were dried in envelopes under laboratory condition for at least 2 weeks and then the seeds were collected.

\section{IMPORTANT NOTES}

(1) The reason we use Ziploc ${ }^{\circledR}$ containers instead of typical tissue culture pots is because Ziploc ${ }^{\circledR}$ container is inexpensive and autoclavable.

(2) It is critical to obtain healthy ppi2-2 plants from plates and use these for subsequent cultivation in Ziploc ${ }^{\circledR}$ containers. Generally, if the ppi2-2 plants are too old or subjected to stress (e.g., accumulation of anthocyanin) on the plates, the rate of success in obtaining seeds is significantly lower. 
(3) Once the lid of the container is opened, it is important to prevent the development of excess humidity in the growth chamber. If the humidity is too high, the flowers of the ppi22 plants will wilt and fail to produce seeds. We usually grow plants at $50 \%$ relative humidity until they set seeds.

(4) As described elsewhere (Shipman-Roston et al., 2010), it is critical to provide $3 \%$ sucrose to support the heterotrophic growth of albino plants. Because high sucrose content also facilitates senescence, we supplied 3\% sucrose only in the Ziploc ${ }^{\circledR}$ containers.

\section{GROWTH CONDITIONS FOR LIGHT EXPOSURE EXPERIMENTS}

Plants were grown on $0.5 \%$ agar medium containing $1 \%$ sucrose and $0.5 \times \mathrm{MS}$ salts at $\mathrm{pH} 5.8$. To synchronize germination, all seeds were maintained in the dark at $4^{\circ} \mathrm{C}$ for 3 days after sowing. After low temperature treatment, seeds were exposed to white light for $8 \mathrm{~h}$ at $22^{\circ} \mathrm{C}$ and then returned to the dark for 4 days. Dark-grown plants were harvested and frozen in liquid nitrogen under a dim green light. A fraction of the dark-grown plants was then exposed to continuous white light for $24 \mathrm{~h}$. After exposure to continuous white light, the plants were harvested and ground in liquid nitrogen for subsequent analysis.

\section{RNA ISOLATION AND REAL-TIME PCR ANALYSIS}

Total RNA was extracted from aerial tissues of wild-type and mutant plants using an RNAiso plus reagent (Takara) as described elsewhere (Kakizaki et al., 2009). We prepared three independent RNA samples for each treatment. Each RNA sample was prepared from $\sim 30$ plants (equivalent to three spots in Figure 4A). cDNA was then synthesized using the PrimeScript ${ }^{\mathrm{TM}}$ RT reagent kit (Takara) using a random hexamer and oligo $\mathrm{d}(\mathrm{T})$ primers. Real-time PCR was performed on a Thermal Cycler Dice RealTime System (Takara) using SYBR Premix Ex Taq II (Takara) as previously described (Kakizaki et al., 2009). The primers used for real-time PCR are listed in Table 1. The transcript level of each gene was normalized to that of ACTIN2.

\section{RESULTS}

\section{CHARACTERIZATION OF SEEDS HARVESTED FROM HOMOZYGOUS} ppi2-2 MUTANTS

We harvested the seeds from the 10 Ziploc $^{\circledR}$ containers $(\sim 50$ plants). The yield of seeds in each experiment depended on the condition of the ppi2-2 plants in the container. After four independent experiments, we obtained $0.26 \mathrm{~g}$ of homozygous ppi2-2 seeds.

To determine whether the harvested seeds could be used for further analysis, we next examined the seeds harvested from wild-type, heterozygous ppi2-2 (ppi2-2/+), and ppi2-2 plants by microscopy. As shown in Figure 3A, the ppi2-2 seeds were elongated in shape compared to those of the wild-type and ppi2-2/+ seeds. Nonetheless, most of these elongated seeds did not look like aborted seeds.

When the wild-type, ppi2-2/+, and ppi2-2 seeds were sown on MS plates, at least $90 \%$ of the wild-type and ppi2-2/+ seeds germinated (Figure 3B). In contrast, only $60 \%$ of the ppi2-2 seeds germinated 6 days after their transfer to the growth chamber (Figure 3B). The reason ppi2-2 seeds exhibited a low germination rate remains unclear. Seed development is divided into two major phases, designated as the embryo and endosperm development phase and the seed maturation phase (West and Harada, 1993). Our previous observation suggested that embryo development of ppi2-2 seeds was normal (Kakizaki et al., 2009). Consistent with this observation, the germination rate of ppi2-2 seeds harvested from the ppi2-2/+ plants was normal (Figure 3B, 25\% of the ppi2-2/+ progeny was ppi2-2). Hence, a possible explanation for the low germination rate of ppi2-2 seeds is insufficient maturation due to high humidity in the pots. It is also possible that the growth retardation of ppi2-2 plants affects the seed development on those plants.

We also investigated the phenotype of seedlings germinated from the wild-type, ppi2-2/+, and ppi2-2 seeds. As shown in Figures 3B,C, all of the wild-type progeny exhibited a green phenotype, whereas $\sim 25 \%$ of the ppi2-2/+ progeny was albino. In contrast, $100 \%$ of the ppi2-2 progeny exhibited an albino phenotype (Figures 3B,C).

In conclusion, we were able to recover viable seeds from homozygous ppi2-2 seedlings. Furthermore, all of the ppi2-2 progeny exhibited an albino phenotype. Although the germination rate of ppi2-2 was relatively low, it was still sufficient to further analyze its progeny. We conclude that our method allows us to harvest seeds from the seedling lethal mutant ppi2-2.

\section{PHOTOMORPHOGENIC RESPONSE IN ppI2-2 MUTANTS: THE NEW METHOD HELPS US FURTHER UNDERSTAND THE ROLES OF PLASTID PROTEINS IN PLANT GROWTH AND DEVELOPMENT}

Obtaining viable seeds from seedling lethal albino plants helps us uncover the roles of plastid proteins in plant growth and

Table 1 | List of gene-specific primers used in real-time PCR analysis.

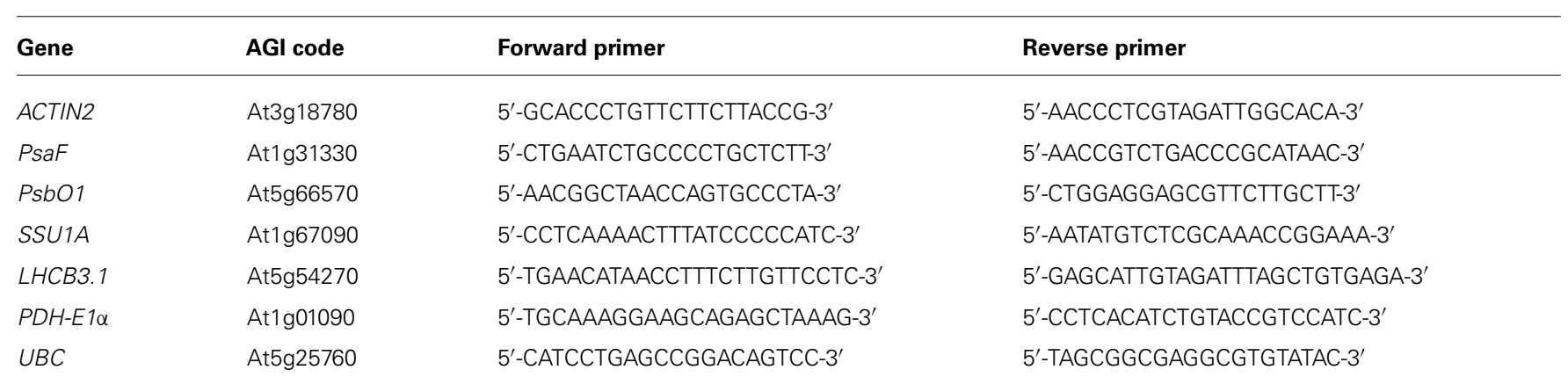


A
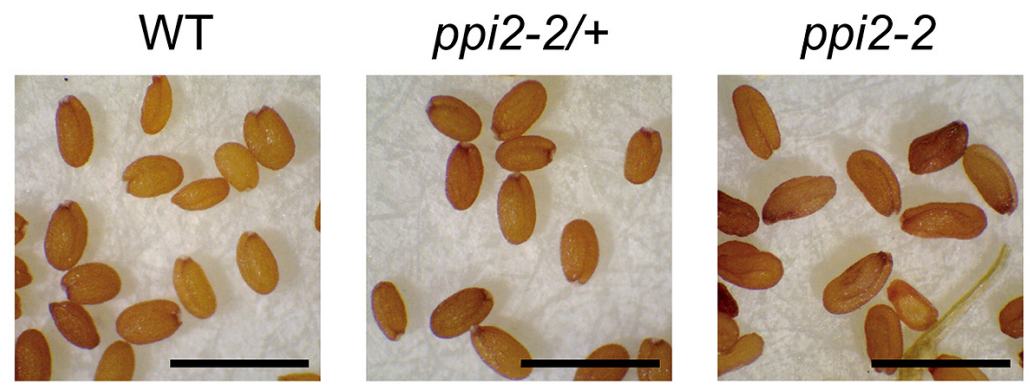

B

\begin{tabular}{|c|c|c|c|c|c|c|c|}
\hline & \multirow[b]{2}{*}{ \# of Seeds } & \multirow{2}{*}{$\begin{array}{c}\text { \# of } \\
\text { Germination }\end{array}$} & \multirow{2}{*}{$\begin{array}{c}\% \text { of } \\
\text { Germination }\end{array}$} & \multicolumn{3}{|c|}{ Seedling phenotype } & \multirow{2}{*}{$\begin{array}{c}\% \text { of } \\
\text { Albinism }\end{array}$} \\
\hline & & & & Green & Albino & N.D. & \\
\hline WT & 214 & 203 & $94.9 \%$ & 200 & 0 & 3 & $0 \%$ \\
\hline ppi2-2/+ & 317 & 317 & $100 \%$ & 239 & 77 & 1 & $24.4 \%$ \\
\hline ppi2-2 & 321 & 196 & $61.1 \%$ & 0 & 188 & 8 & $100 \%$ \\
\hline
\end{tabular}

C
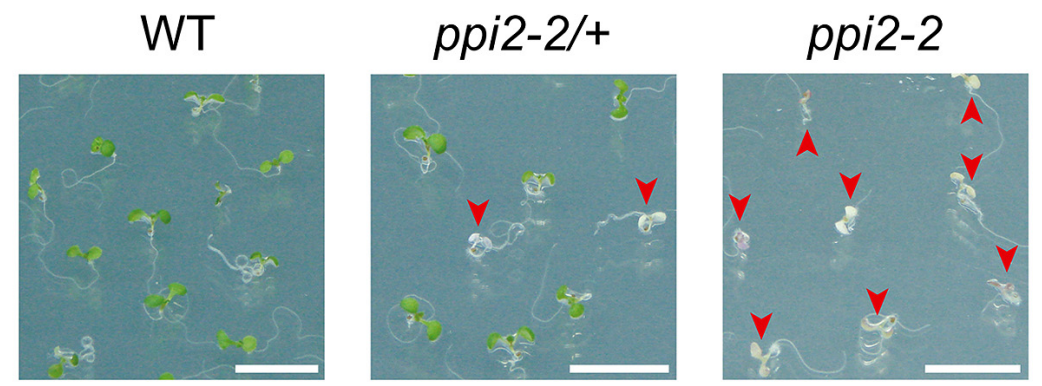

FIGURE 3 | Analysis of seeds derived from wild-type, heterozygous ppi2-2, and homozygous ppi2-2 plants. (A) The appearance of dry seeds derived from wild-type (WT), heterozygous ppi2-2 (ppi2-2/+), and homozygous ppi2-2 (ppi2-2) plants. Black bars $=$ approximately $1 \mathrm{~mm}$.

(B) Analysis of germination rate and seedling phenotypes. Phenotypes were determined 6 days after the transfer of the plates to a growth chamber. Some of those seedlings could not be designated as green or albino due to growth retardation and thus were classified as "not determined (N.D.)."

(C) Phenotype of seedlings germinated from wild-type, ppi2-2/+, and ppi2-2 seeds. Arrowheads indicate albino plants. White bars $=$ approximately $1 \mathrm{~cm}$. development in more detail. For instance, the role of plastid protein import in a photomorphogenic response remains unclear. This is because we cannot discriminate between ppi2-2/+ and ppi2-2 seedlings grown in the dark. When wild-type, $p$ pi2-2/+, and ppi2-2 seeds were germinated and grown in the dark for 4 days, all of the plants exhibited an etiolated phenotype regardless of their genotype (Figure 4A, upper panel). When wild-type plants were exposed to continuous white light for $24 \mathrm{~h}$, their cotyledons turned green (Figure 4A, lower left panel). In contrast, ppi2-2 plants opened their cotyledons after $24 \mathrm{~h}$ of light illumination, although they did not turn green (Figure 4A, lower right panel). The ppi2$2 /+$ progeny turned green upon light illumination, whereas the segregated ppi2-2 plants did not exhibit greening (Figure 4A, lower middle panel).

We next investigated the expression of photosynthesis-related genes upon light illumination in ppi2-2 plants. For this analysis, we chose nuclear-encoded genes involved in photosynthetic electron transport ( $P s a F, P s b O 1$, and $L H C B 3.1$ ) and $\mathrm{CO}_{2}$ fixation (SSU1A). In the wild-type, the expression of photosynthesis-related genes such as PsaF, PsbO1, SSU1A, and LHCB3.1 was induced upon light illumination (Figure 4B, left panel). In contrast, light induction of these genes was compromised in the ppi2-2 mutant (Figure 4B, left panel). We also confirmed that the expression of non-photosynthetic genes encoding pyruvate dehydrogenase $\mathrm{E} 1 \alpha$ subunit $(P D H-E 1 \alpha)$ and ubiquitin conjugating enzyme (UBC). These genes have been shown to be expressed constitutively in Arabidopsis (Ivanova et al., 2004; Czechowski et al., 2005). As shown in Figure 4B (right panel), they did not show strong induction upon illumination. These data indicate that functional TOC machinery is a prerequisite for the rapid induction of photosynthesis-related genes upon light illumination. This also suggests that a tight coordination between plastid protein import and light-regulated gene expression would help prevent the accumulation of non-imported precursor proteins in the cytosol. 


\section{A}

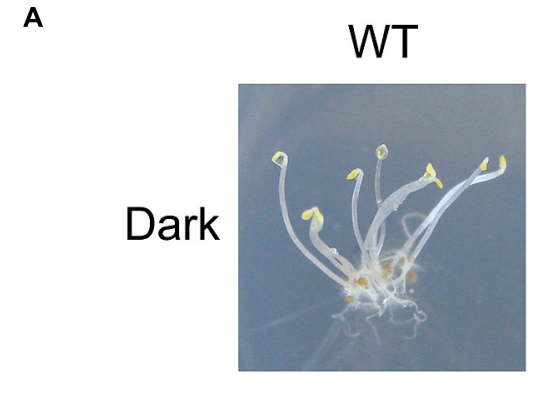

ppi2-2/+

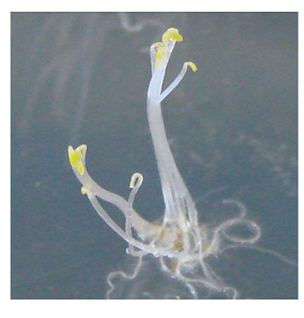

ppi2-2
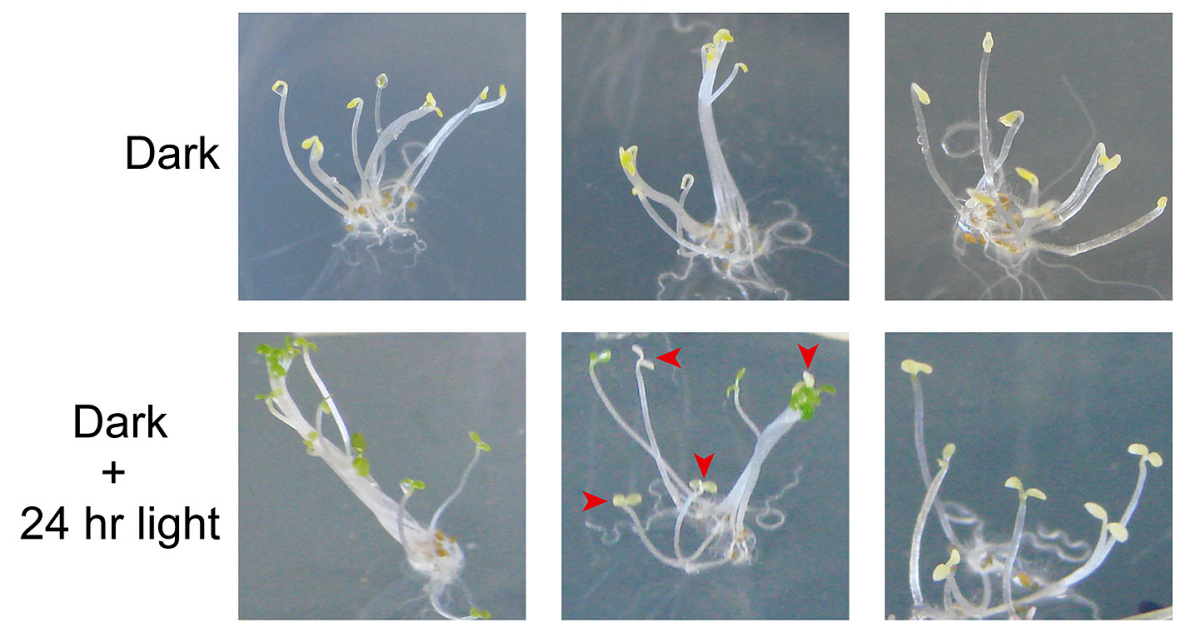

B

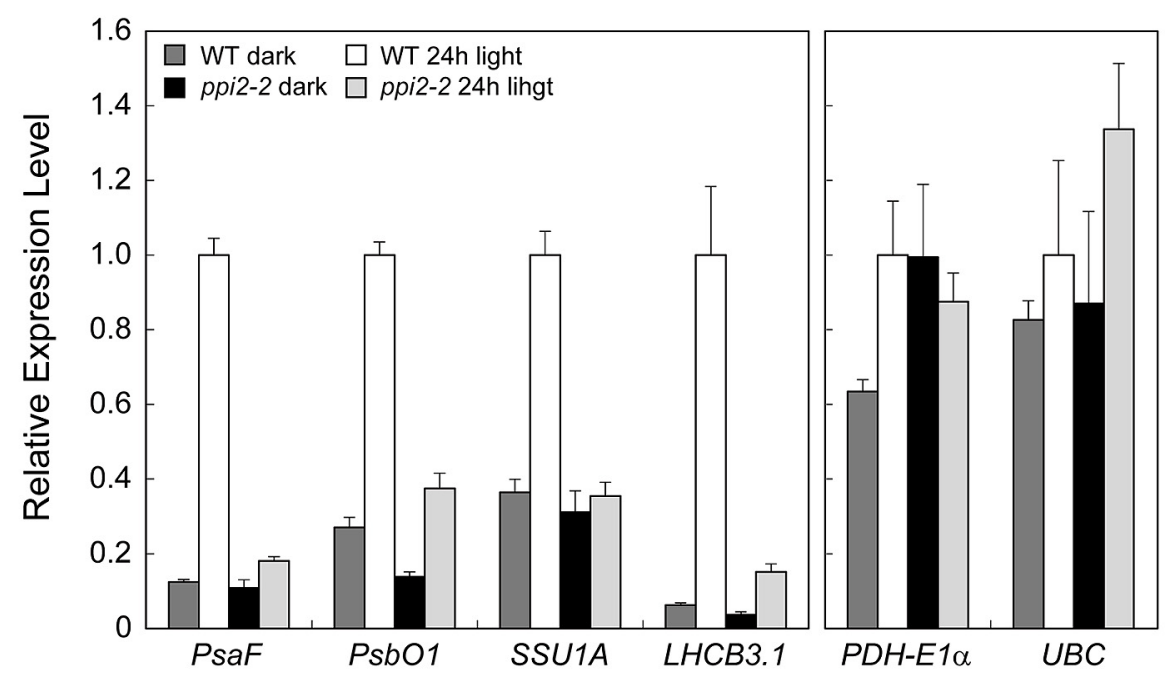

FIGURE 4 | The light response of seedlings germinated from wild-type (WT), heterozygous ppi2-2 (ppi2-2/+), and homozygous ppi2-2 (ppi2-2) seeds. (A) Phenotype of wild-type, ppi2-2/+, and ppi2-2 progenies grown in the dark (Dark). The plants were then exposed to continuous white light for $24 \mathrm{hr}$ (Dark $+24 \mathrm{hr}$ light). Arrowheads indicate homozygous ppi2-2 plants found in the ppi2-2/+ progeny.
(B) Response of photosynthesis-related (left) and non-photosynthetic (right) genes upon light illumination. Expression levels were analyzed by real-time PCR and normalized to that of ACTIN2. The expression level in the light-illuminated wild-type (WT 24-h light) was set to 1. Each bar represents the mean of three independent samples. Error bars represent 1 SE.

\section{CONCLUSION AND POSSIBLE APPLICATIONS}

This report describes a method for obtaining viable seeds from the seedling lethal ppi2-2 mutant using Ziploc ${ }^{\circledR}$ containers. Four independent experiments allowed us to obtain $\sim 10,000(0.26 \mathrm{~g})$ homozygous ppi2-2 seeds. We also confirmed that at least $60 \%$ of the harvested seeds were able to germinate (Figure 3B). Establishment of this new growth method allowed us to analyze the roles of plastid protein import in light-induced gene expression. Characterization of the homozygous ppi2-2 progeny revealed that ppi2-2 mutants failed to induce photosynthesisrelated genes upon light illumination (Figure 4). This indicates that the integrity of the protein import apparatus plays a critical role in the rapid induction of photosynthesis-related genes upon light illumination. In contrast, the ppi2-2 mutation did not affect cotyledon opening upon light illumination (Figure 4A). These results demonstrated that investigations involving the progeny of homozygous albino plants will help us further understand the role of plastid protein import in plant growth and development.

Although we used ppi2-2 plants as the model in our experiments, we would like to propose that the method could be applied to other Arabidopsis mutants that are described as "seedling 
Table 2 | List of seedling lethal Arabidopsis mutants lacking an outer or inner envelope chloroplast membrane protein.

\begin{tabular}{|c|c|c|c|}
\hline Mutant name & AGI code & Localization & Reference \\
\hline \multirow[t]{2}{*}{ ppi2 (toc159) } & At4g02510 & OM & Bauer et al. (2000), \\
\hline & & & Kakizaki etal. (2009) \\
\hline tic20-I & At1g04940 & $\mathrm{IM}$ & Teng et al. (2006) \\
\hline \multirow[t]{2}{*}{ cia5/pic1 } & At2g15290 & $\mathrm{IM}$ & Teng etal. (2006), \\
\hline & & & Duy et al. (2007) \\
\hline plsp1 & At3g24590 & Env/Thy & Inoue et al. (2005) \\
\hline apg1 & At3g63410 & $\mathrm{IM}$ & Motohashi etal. (2003) \\
\hline tic100 & At5g22640 & $\mathrm{IM}$ & Kikuchi et al. (2013) \\
\hline tic56 & At5g01590 & $\mathrm{IM}$ & Kikuchi et al. (2013) \\
\hline mgd1 & At4g31780 & $\mathrm{IM}$ & Kobayashi etal. (2007) \\
\hline vipp1 & At1g65260 & IM/Thy & Zhang et al. (2012) \\
\hline
\end{tabular}

OM, outer envelope membrane; $I M$, inner envelope membrane; Env, envelope membrane; Thy, thylakoid membrane.

lethal." Table 2 shows a comprehensive list of seedling lethal Arabidopsis mutants lacking either an outer or inner envelope membrane protein in chloroplasts. Because many mutants that are defective in an envelope membrane protein exhibit an embryo lethal phenotype (Hormann etal., 2004; Baldwin etal., 2005; Inaba et al., 2005; Patel et al., 2008; Hsu et al., 2010), the number of albino mutants that can be used for investigations is limited. Instead, we found that the method can be extended to other albino mutants. It has been suggested that a number of seedling lethal Arabidopsis mutants are associated with chloroplast dysfunction (Budziszewski et al., 2001). An exhaustive analysis of Arabidopsis mutants lacking a chloroplast protein revealed that more than 50 mutants exhibited albino, pale green, and other chloroplast-associated phenotypes (Myouga etal., 2010). Hence, we anticipate that seeds from some of these albino/seedling lethal mutants can be obtained using our method.

In summary, we have developed a method for recovering viable seeds from the seedling lethal Arabidopsis mutant ppi2-2. Our method can be applied to other albino Arabidopsis mutants, helping us further understand the roles of chloroplast proteins in plant growth and development.

\section{ACKNOWLEDGMENTS}

This work was supported by Grant-in-Aid for Young Scientists (B, no. 25850073) and Strategic Young Researcher Overseas Visits Program for Accelerating Brain Circulation from MEXT, and a grant for Scientific Research on Priority Areas from the University of Miyazaki.

\section{REFERENCES}

Baldwin, A., Wardle, A., Patel, R., Dudley, P., Park, S. K., Twell, D., et al. (2005). A molecular-genetic study of the Arabidopsis Toc75 gene family. Plant Physiol. 138, 715-733. doi: 10.1104/pp.105.063289

Bauer, J., Chen, K., Hiltbunner, A., Wehrli, E., Eugster, M., Schnell, D., et al. (2000). The major protein import receptor of plastids is essential for chloroplast biogenesis. Nature 403, 203-207. doi: 10.1038/35003214
Budziszewski, G. J., Lewis, S. P., Glover, L. W., Reineke, J., Jones, G., Ziemnik, L. S., et al. (2001). Arabidopsis genes essential for seedling viability: isolation of insertional mutants and molecular cloning. Genetics 159, 17651778.

Chou, M. L., Fitzpatrick, L. M., Tu, S. L., Budziszewski, G., Potter-Lewis, S., Akita, M., etal. (2003). Tic40, a membrane-anchored co-chaperone homolog in the chloroplast protein translocon. EMBO J. 22, 2970-2980. doi: 10.1093/emboj/cdg281

Constan, D., Froehlich, J. E., Rangarajan, S., and Keegstra, K. (2004a). A stromal Hsp100 protein is required for normal chloroplast development and function in Arabidopsis. Plant Physiol. 136, 3605-3615. doi: 10.1104/pp.104.052928

Constan, D., Patel, R., Keegstra, K., and Jarvis, P. (2004b). An outer envelope membrane component of the plastid protein import apparatus plays an essential role in Arabidopsis. Plant J. 38, 93-106. doi: 10.1111/j.1365-313X.2004.02024.x

Czechowski, T., Stitt, M., Altmann, T., Udvardi, M. K., and Scheible, W. R. (2005). Genome-wide identification and testing of superior reference genes for transcript normalization in Arabidopsis. Plant Physiol. 139, 5-17. doi: 10.1104/pp.105.063743

Duy, D., Wanner, G., Meda, A. R., Von Wiren, N., Soll, J., and Philippar, K. (2007). PIC1, an ancient permease in Arabidopsis chloroplasts, mediates iron transport. Plant Cell 19, 986-1006. doi: 10.1105/tpc.106.047407

Dyall, S. D., Brown, M. T., and Johnson, P. J. (2004). Ancient invasions: from endosymbionts to organelles. Science 304, 253-257. doi: 10.1126/science.1094884

Hormann, F., Kuchler, M., Sveshnikov, D., Oppermann, U., Li, Y., and Soll, J. (2004). Tic32, an essential component in chloroplast biogenesis. J. Biol. Chem. 279, 34756-34762. doi: 10.1074/jbc.M402817200

Hsu, S. C., Belmonte, M. F., Harada, J. J., and Inoue, K. (2010). Indispensable roles of plastids in Arabidopsis thaliana embryogenesis. Curr. Genomics 11, 338-349. doi: $10.2174 / 138920210791616716$

Inaba, T., Alvarez-Huerta, M., Li, M., Bauer, J., Ewers, C., Kessler, F., et al. (2005). Arabidopsis ticl 10 is essential for the assembly and function of the protein import machinery of plastids. Plant Cell 17, 1482-1496. doi: 10.1105/tpc.105.030700

Inaba, T., and Schnell, D. J. (2008). Protein trafficking to plastids: one theme, many variations. Biochem. J. 413, 15-28. doi: 10.1042/BJ20080490

Inoue, K., Baldwin, A. J., Shipman, R. L., Matsui, K., Theg, S. M., and OhmeTakagi, M. (2005). Complete maturation of the plastid protein translocation channel requires a type I signal peptidase. J. Cell Biol. 171, 425-430. doi: $10.1083 /$ jcb.200506171

Ivanova, Y., Smith, M. D., Chen, K., and Schnell, D. J. (2004). Members of the Toc159 import receptor family represent distinct pathways for protein targeting to plastids. Mol. Biol. Cell 15, 3379-3392. doi: 10.1091/mbc.E03-12-0923

Jarvis, P., Chen, L.-J., Li, H., Peto, C. A., Fankhauser, C., and Chory, J. (1998). An Arabidopsis mutant defective in the plastid general protein import apparatus. Science 282, 100-103. doi: 10.1126/science.282.5386.100

Jarvis, P., and Lopez-Juez, E. (2013). Biogenesis and homeostasis of chloroplasts and other plastids. Nat. Rev. Mol. Cell Biol. 14, 787-802. doi: 10.1038/nrm3702

Kakizaki, T., Matsumura, H., Nakayama, K., Che, F. S., Terauchi, R., and Inaba, T. (2009). Coordination of plastid protein import and nuclear gene expression by plastid-to-nucleus retrograde signaling. Plant Physiol. 151, 1339-1353. doi: 10.1104/pp.109.145987

Kessler, F., Blobel, G., Patel, H. A., and Schnell, D. J. (1994). Identification of two GTP-binding proteins in the chloroplast protein import machinery. Science 266, 1035-1039. doi: 10.1126/science.7973656

Kikuchi, S., Bedard, J., Hirano, M., Hirabayashi, Y., Oishi, M., Imai, M., et al. (2013). Uncovering the protein translocon at the chloroplast inner envelope membrane. Science 339, 571-574. doi: 10.1126/science.1229262

Kobayashi, K., Kondo, M., Fukuda, H., Nishimura, M., and Ohta, H. (2007). Galactolipid synthesis in chloroplast inner envelope is essential for proper thylakoid biogenesis, photosynthesis, and embryogenesis. Proc. Natl. Acad. Sci. U.S.A. 104, 17216-17221. doi: 10.1073/pnas.0704680104

Kovacheva, S., Bedard, J., Patel, R., Dudley, P., Twell, D., Rios, G., et al. (2005). In vivo studies on the roles of Tic110, Tic40 and Hsp93 during chloroplast protein import. Plant J. 41, 412-428. doi: 10.1111/j.1365-313X.2004.02307.x

Kubis, S., Patel, R., Combe, J., Bedard, J., Kovacheva, S., Lilley, K., et al. (2004). Functional specialization amongst the Arabidopsis Toc159 family of chloroplast protein import receptors. Plant Cell 16, 2059-2077. doi: 10.1105/tpc.104.023309

Li, H. M., and Chiu, C. C. (2010). Protein transport into chloroplasts. Annu. Rev. Plant Biol. 61, 157-180. doi: 10.1146/annurev-arplant-042809-112222 
Motohashi, R., Ito, T., Kobayashi, M., Taji, T., Nagata, N., Asami, T., et al. (2003). Functional analysis of the $37 \mathrm{kDa}$ inner envelope membrane polypeptide in chloroplast biogenesis using a Ds-tagged Arabidopsis pale-green mutant. Plant J. 34, 719-731. doi: 10.1046/j.1365-313X.2003.01763.x

Myouga, F., Akiyama, K., Motohashi, R., Kuromori, T., Ito, T., Iizumi, H., et al. (2010). The chloroplast function database: a large-scale collection of Arabidopsis Ds/Spm- or T-DNA-tagged homozygous lines for nuclear-encoded chloroplast proteins, and their systematic phenotype analysis. Plant J. 61, 529-542. doi: 10.1111/j.1365-313X.2009.04074.x

Patel, R., Hsu, S. C., Bedard, J., Inoue, K., and Jarvis, P. (2008). The Omp85-related chloroplast outer envelope protein OEP80 is essential for viability in Arabidopsis. Plant Physiol. 148, 235-245. doi: 10.1104/pp.108.122754

Schnell, D. J., Kessler, F., and Blobel, G. (1994). Isolation of components of the chloroplast protein import machinery. Science 266, 1007-1012. doi: 10.1126/science.7973649

Shipman-Roston, R. L., Ruppel, N. J., Damoc, C., Phinney, B. S., and Inoue, K. (2010). The significance of protein maturation by plastidic type I signal peptidase 1 for thylakoid development in Arabidopsis chloroplasts. Plant Physiol. 152, 1297 1308. doi: 10.1104/pp.109.151977

Teng, Y. S., Su, Y. S., Chen, L. J., Lee, Y. J., Hwang, I., and Li, H. M. (2006). Tic21 is an essential translocon component for protein translocation across the chloroplast inner envelope membrane. Plant Cell 18, 2247-2257. doi: 10.1105/tpc.106. 044305
West, M., and Harada, J. J. (1993). Embryogenesis in higher plants: an overview. Plant Cell 5, 1361-1369. doi: 10.1105/tpc.5.10.1361

Zhang, L., Kato, Y., Otters, S., Vothknecht, U. C., and Sakamoto, W. (2012). Essential role of VIPP1 in chloroplast envelope maintenance in Arabidopsis. Plant Cell 24, 3695-3707. doi: 10.1105/tpc.112.103606

Conflict of Interest Statement: The authors declare that the research was conducted in the absence of any commercial or financial relationships that could be construed as a potential conflict of interest.

Received: 28 March 2014; accepted: 13 May 2014; published online: 04 June 2014.

Citation: Tada A, Adachi F, Kakizaki T and Inaba T (2014) Production of viable seeds from the seedling lethal mutant ppi2-2 lacking the atToc159 chloroplast protein import receptor using plastic containers, and characterization of the homozygous mutant progeny. Front. Plant Sci. 5:243. doi: 10.3389/fpls.2014.00243

This article was submitted to Plant Cell Biology, a section of the journal Frontiers in Plant Science.

Copyright (c) 2014 Tada, Adachi, Kakizaki and Inaba. This is an open-access article distributed under the terms of the Creative Commons Attribution License (CC BY). The use, distribution or reproduction in other forums is permitted, provided the original author(s) or licensor are credited and that the original publication in this journal is cited, in accordance with accepted academic practice. No use, distribution or reproduction is permitted which does not comply with these terms. 